\title{
The power of sports tradition and its influence on long-standing engagement of athletes in running races
}

\author{
Miloš Bednář
}

Faculty of Physical Education and Sport, Charles University, Prague, Czech Republic bednar@fttvs.cuni.cz

\begin{abstract}
Analysis of the general role of tradition formed wider theoretical background of the paper. We used hermeneutic analysis to interpret this role. We attempted to formulate own definition of tradition using the term of social time. Well-known world competitions served as an example of power of tradition in the field of sport. Special attention was paid to the Olympic movement and two parallel but different inspirations from the heritage of the ancient Olympism in the case of the Sokol sports and social movement and the Modern Olympics.

In a longitudinal study we researched a group of runners who participated repeatedly in the $10 \mathrm{~K}$ Czech race "Běchovice - Praha". It was founded in 1897 and has been held each consecutive year. Our aim was to illustrate how the tradition of one race can engage runners in lifelong physical activities. We found 322 runners who participated 20 times and more. Constancy of the route, non-stop organizing, engagement of the whole families, celebrations of anniversaries, and wider publicity were found to be factors in building loyalty to the race. We discussed some aspects of comparison with similar studies as well. Particular attention was paid to the Boston Marathon and especially to means of supporting loyalty of runners.
\end{abstract}

\section{KEYWORDS}

lifelong physical activities; long-distance running; philosophy of history; sport history

DOI

10.14712/23366052.2019.6

(c) 2019 The Author. This is an open-access article distributed under the terms of the Creative Commons Attribution License (http://creativecommons.org/licenses/by/4.0), which permits unrestricted use, distribution, and reproduction in any medium, provided the original author and source are credited. 


\section{INTRODUCTION}

Various academic disciplines use the word tradition in a variety of ways. According to the universally accepted definition of sociologist Edward Shils, "tradition is anything which is transmitted or handed down from the past to the present ..." (Shils, 1981, p. 12). A set of questions arises here: What exactly is this "anything"? What is the meaning of tradition in history? What is the role of tradition in our personal lives? How important role can tradition play in the field of sport? Searching for answers shaped motivation to arrange our research.

We decided to combine two approaches: a philosophical one interpreting the role of tradition both in general and in the field of sports, and a descriptive statistical one following a special group of runners participating at one race with a long tradition over a long period.

The 10K Czech road run named "Běchovice - Praha" was founded in 1897 and has been hosted consecutively each year, that is, 122 times (including the race in the year 2018). The number of participating runners has increased each year: a few individuals before World War I, numbers ranging between ten and one hundred between the World Wars, several hundred after World War II and several thousand since 1971. At the same time, there was an increase in repeated performances; runners wanted to continue in participating even after they had already reached their peak performances. In 1922 (the race's 25 th anniversary) the first race for "veterans" was organized. This became a regular occurrence in the key anniversary years and since 1956, regular races for race veterans have been organized. Since this time, the run has opened for all levels of performance (the only limitation is a finish time under two hours). It is necessary to say that the route is very hilly and it is not possible to run it without good training ahead of time.

It was not long before reporters began to pay attention not only to winners but also to the runners who were able to finish multiple times. From the end of 1920's the participants with the most lifetime races run were specially recognized during the closing ceremony. In 1940 the first runner was recognized as having achieved 20 finishes; in 1956 the same runner achieved 30 finishes; in 1973 a different runner achieved 40 finishes; and in 1989 another runner achieved 50 finishes. This achievement drove researchers to collect the special group of runners who had participated 20 times or more, and we began to track their effort to gain the utmost number of finishes.

Yet another facet arose: the more ambitious among these loyal runners (they have founded their own "Club of Loyal Runners") are motivated not only to participate but also to show their best performance at a given time. From this we began to create special statistics and lists of records in relation to age through the lens of a life-long perspective. The first book about these and other aspects as well as the special "philosophy" of this run was published in 2011 (Bednář, 2011). We also aspired to influence the behavior of runners through their engagement in tradition, in other words, to join theory and practice.

It is evident that the long tradition of this road run plays an important role in motivating runners to participate. How strong is this role? Which features of the tradition are attractive for fans? What is especially important for the race's sustainment, establishment, continuation and development? More distant horizons emerged, revealing of studying wider contexts first. 


\section{METHODS}

We used hermeneutic analysis to interpret the role of tradition both in general and in the field of sports. We especially tried to follow the wider context of investigated topics according to hermeneutic proposition that "the text without context is only pretext". Our own definition of tradition was one of results.

After gathering of all results rosters (122 rosters) we searched for runners who participated 20 times or more in "Běchovice - Praha" road race - it was done systematically for the time period of the last 25 years (digitization of the rosters was first implemented in 2016).

Further we examined this special group of runners, performing a descriptive statistical evaluation that factored age, performances and duration of involvement. We also created a particular statistical set measuring the participation of whole families to follow the branching of tradition. The output of this approach was the construct of two types of tradition.

\section{TRADITION}

The above cited definition of Edward Shils proclaims that tradition is "anything which is transmitted or handed down". What can be a valuable springboard strong enough to give birth to a tradition? Our answer is this: Tradition arises when something that is important and meaningful for some society is transferred ${ }^{1}$ and anchored in its social practice. Yet more questions may arise; for example, what concrete idea or practice can be important and meaningful? Shils answers, speaking on the substance of tradition: "All accomplished patterns of the human mind, all patterns of belief or modes of thinking, all achieved patterns of social relationships, all technical practices, and all physical artefacts or natural objects are susceptible to becoming objects of transmission; each is capable of becoming a tradition" (Shils, 1981, p. 16). We cannot simply automatically agree with quoted claims; we must consider real substance, i.e. something physical that is capable of carrying a valuable legacy or message. It is necessary to research symbolic meaning or special significance as well.

After the birth of a tradition, there is the task to preserve it for the future. There is no small risk of traditions being lost, especially in times often identified as post-traditional. Which elements can ensure the preservation and continuation of tradition? Anthony Giddens, another sociologist, names several elements and especially rituals (Giddens, 1994). They are repeatable so that they can stabilize behavior in societies. Yet all traditions need own followers or "faithful custodians" as well: "traditum (what is transmitted) might have become altered from its earliest forms in many respects but not in those regarded as central by its custodians" (Shils, 1981, p. 14).

These custodians can be called pure traditionalists. Radical traditionalists are the second type - they keep the shield of tradition but don't regard any part as central and are ready to change any parts step by step. The well known "paradox of grandfa-

The word "tradition" itself derives from the Latin tradere, what literally means to transmit, to hand over, or to give for safekeeping. 
ther's axe" ${ }^{2}$ could be their motto. We believe that a balanced position is optimal for the "survival" of tradition. It needs both prolongation within time and development. German philosopher Hans-Georg Gadamer pointed out that development of tradition isn't something spontaneous or mechanical, and needs engagement and care from followers (Gadamer, 2004).

There are very old traditions like the Jewish Shabbat, or Greek Olympic Games, yet there are also so called "invented traditions", introduced by Eric Hobsbawm. He said about this term: "It includes both 'traditions' actually invented, constructed and formally instituted and those emerging in a less easily traceable manner within a brief and dateable period ... and establishing themselves with great rapidity" (Hobsbawm \& Ranger, 1992, p. 1).

Shil's definition references the transfer of a tradition from the past to the present. To follow this line of transfer is often the task for historians, using the wider concept of historical time. Yet we have also quoted sociologists and philosophers, and we are going to continue our research within one area of social activities, i.e. sport. It can be argued that studies of the temporal dimension of such activities and processes should be based on the concept of social time. Thus, Mark Elchardus, in his discussion of the new role of time in sociological theory, proposes to focus on social temporality (Elchardus, 1988). We mean that this approach can be a good framework for reflections concerning tradition.

We can conclude that tradition is a special continuity of social time, beginning with a certain valuable spring and carrying some legacy, message, symbolic meaning, or special significance, then taking shape within the social memory and historical consciousness. Tradition thus becomes a source for a better understanding of history which can help cement social practice.

\section{Tradition in the field of sports}

Are we living in a post-traditional sports society? We cannot share this attitude of Giddens, although the business imperative of constant innovation and revision has supporters amongst people involved in sports management. Their attitude is seen in the forced effort to change the route, distance or rules of the race each year. Yet we can see the opposite approach, using the power of tradition, as prevailing. The power of tradition is demonstrated in competitions like Wimbledon, the Tour de France, the Davis Cup, the Stanley Cup, the Super Bowl, the Boston Marathon, etc. While the first five named events are for elite athletes, the Boston Marathon is open to the entire population of runners ${ }^{3}$ as is the case of the Czech "Běchovice - Praha". This is important for the sharing of a tradition which isn't formed only by the winners and their records. Participating runners can be a part of the annual "moveable feast" within "moveable tradition". Of course, direct spectators also share a concrete tradition in a particular second circle and another group of TV viewers and followers on social media are part

2 A man proclaims in the old ancient saying: "This is my grandfather's axe. My father replaced the handle and I replaced the head." It's about problem of identity: of the axe itself, and/or of its role.

3 There is certain restriction of participation during the last years due to field size limitations, as well as a heightened interest of runners. 
of a particular third circle. All these people - directly, or indirectly - support tradition and demonstrate its power.

A very special case is the Olympic Games with the duration of 1168 years in ancient times and 122 years in modern times. The Modern Olympics can be assigned to the aforementioned theoretical concept of "invented tradition". They may be further assigned to a subcategory of "half-invented tradition" because something new was born in an effort to rekindle the spirit of the Ancient Olympics of Greece, which had been abolished as a pagan cult practice in 393 A.D. The modern Olympic Games were initiated in the 1890's thanks to Pierre de Coubertin, a French educator, who introduced the plan to revive the Olympics. We cannot forget the inspiration of successful excavations of the Ancient Olympia, the site of the Olympic games in ancient times, especially those excavations led by Ernst Curtius in 1875-1881. Coubertin was heavily involved in all aspects of the Games' inception and presided personally over the Olympic Committee for some 30 years. He is responsible for writing the Olympic Charter and Protocol, the Athletes' Oath, and the guidelines for the opening and closing ceremonies of the Games. We can see a special mixture of old tradition and new ideas in these symbols and organisation documents.

The whole history especially of the Modern Olympics is well-known; we would like to add another - and different - case of following the old Olympic tradition: the Sokol sports and social movement. It was founded in Prague in 1862, especially by effort of Miroslav Tyrš. Within the first years the Sokol expanded beyond Prague, first into the Slovenian regions of the Habsburg empire but very soon also into the United States, where the first Sokol unit was formed in St. Louis in 1865 (Nolte, 2009). It is outside the scope of our investigation to follow further history of this organization, yet we can summarize that the Sokol played an important role both in the Middle European politics and in the area of physical culture.

Our task is having a look at a special philosophy of this organization. Tyrš was educator like Coubertin (he had a career as a teacher of aesthetics) and both were inspired with old Greek concept of kalokagathia, ideal of the complete human personality, harmonious in mind and body. The other key values of the Sokol were: health, integrity, well-being, strength, and military capacity. Tyrš took the last value just from the real life of ancient Greeks - it was expected that gymnastic training would contribute to national defense. All these values are still valid, except that the military dimension has been replaced with tradition. Today (after more than 150 years of history) the Sokol can be marked as a physical culture society, or an all-age gymnastics organization taking pride in massive gymnastics rallies. And here we can find basic differences when compared to the Olympic movement: the Sokol's "all-age categories" and "sport for masses" approach, versus the Olympics" "age of maximum results" and "elite" approach. Coubertin is connected to an oft-quoted motto that to take part is more than to win, but at the end of his life (1935) he pointed out something else in speaking about the philosophic foundation of modern Olympism: "The second characteristic (after religion) of Olympism is that it is an aristocracy, an elite ... Of course, this aristocracy is completely egalitarian in origin since membership is determined solely by the physical superiority of the individual ... Yet being elite is not enough. The elite must also be a knighthood" (Coubertin, 2000, pp. 580-581). The message is nevertheless obvious, and is confirmed by the development of elite sports through Olympism. 
Time softened the sharp differences between both organizations: the IOC speaks more about mass commitment to sport; the Sokol became more competitive and did not stop its members from participating in the Olympic Games (several gymnasts in particular gained some gold medals for Czechoslovakia between 1924 and 1968). In any case we could see two parallel but different inspirations from the heritage of the ancient Olympism.

The question arises in the introduction to this article: What is especially important for sustaining, establishing, continuing, and developing tradition? A lot of answers could be gained from the great sports events named above; we tested the situation with the aforementioned "Běchovice - Praha" road race. Given that the route here has been the same since the race's inception, we can compare the best overall results. Furthermore, each runner can compare their own personal results over the course of their lifetime. Here lies the perfect area of comparisons of different types.

\section{RESULTS}

We have found 322 runners (including 12 women) who participated 20 times and more in history of the race. ${ }^{4}$ They form our research cohort. In this cohort, 44 runners are deceased, having an average age 79.91 years old at time of death. The average age of the 278 living runners is 70.06 years old.

\section{The participation aspect from the lifelong perspective}

Nine of runners were able to run 50 times and more; the leader is Vladimír Kř́žz (born 1943) who was able to run 56 times (1963-2018). He is also the leader of another ranking - most consecutive "Běchovice - Praha" runs completed. We have found 74 runners in history of the race capable of non-stop participation from 25 to 56 times (29 runners still continue). Věnceslava Pokorná (born 1948) is the only woman among these with 30 consecutive runs (she also leads the parallel list of faithful women runners with 37 completed runs between 1980 and 2018).

Continuing the list of runners who ran the race repeatedly, we can find:

40-49 times ............. 34 runners

30-39 times .............121 runners (incl. 1 woman $^{6}$ )

20-29 times .............158 runners (incl. 11 women)

A total of 136 runners are still active (defined as participating in the race in 2017 and/or 2018) from this "loyal group", indicating strong loyalty to the race. ${ }^{7}$ This loyalty was built progressively especially after 1990. In this year, the first statistics booklet for the "Běchovice - Praha" run was published and at this point only 12 runners had at least 27 runs. Repeated publicity in the following years formed extrinsic motivation for "unknown heroes" to be part of this exclusive society - beside the intrinsic motivation of accomplishing ${ }^{8}$ one's own running goals.

${ }_{4}$ All data are collected including the race in 2018.

5 To run and to finish - we take into account (in the whole ranking) only successfully finished runs.

6 Women could start only from 1972.

7 Complete and current statistics concerning the road race "Běchovice - Praha" are available at https://www.ftvs.cuni.cz/FTVS-693-version1-bechbrozura18.pdf.

8 We follow self-determination theory of motivation (Deci \& Ryan, 1985). 
Loyalty is also demonstrated in the years of significant anniversary when attendance sharply increases. It is seen especially in the 25 th, 50th, 75 th and 100 th anniversary, noticeably in the first significant anniversary in 1922 and the last one in 1996:
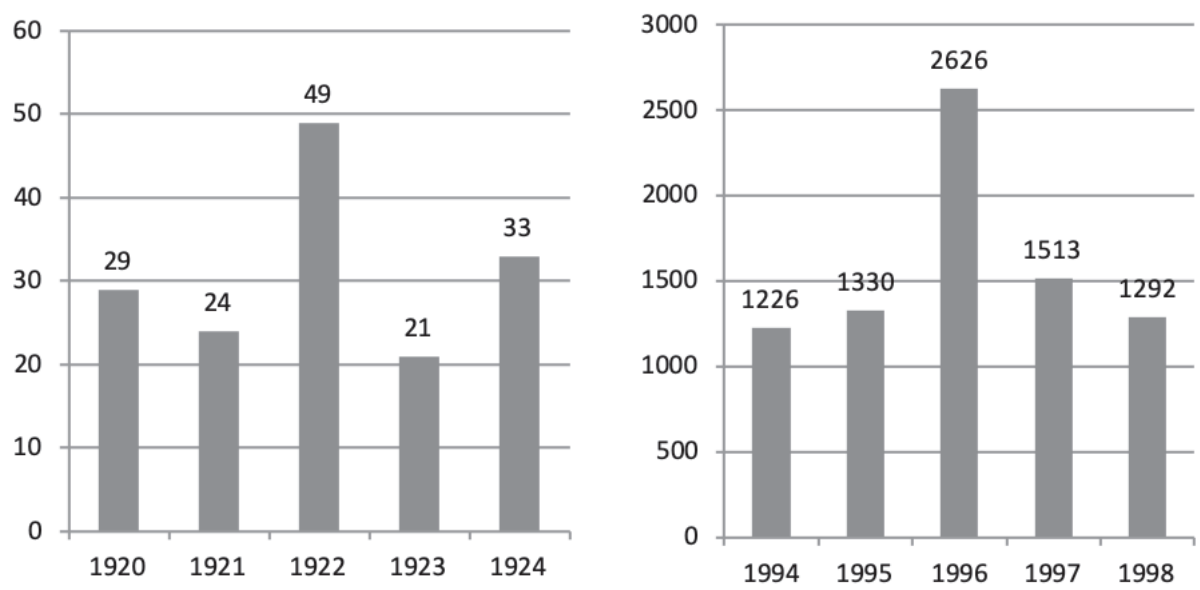

Figure 1 Demonstration of attendance increase in the years of significant anniversary (1922 and 1996)

This fact was emphasized in the 100th anniversary when the number of runners older than 40 was considerably higher than the number of younger runners (1503:911). A lot of older runners came to say goodbye to the race of their heart.

We see how a "big" tradition can breed "smaller" traditions of individuals. Yet another type of loyalty was found: the loyalty of whole families. The loyal runners became good example for those in their surroundings and especially for their children, partners and relatives. As a result, there are eight families with 64-147 runs by individuals. Here are some of the leading families:

The Hák family, 147 runs (14 members beginning in 1965, 2 generations)

The Fiala family, 122 runs (13 members beginning in 1944, 3 generations)

The Bednár family, 117 runs (9 members beginning in 1947, 4 generations)

The statistical analysis measured married couples and other family relationships ( 3 brothers; grandfather, father and son, etc.) as well. From this we may address the branching of tradition.

\section{The performance aspect from the lifelong perspective}

Do older runners still have performance aspirations? Can older runners be engaged in the "Běchovice - Praha" tradition through appreciation of their performances as well? Our research and experiences say YES in both cases.

The age of living runners from our cohort is from 43 to 92 years ( 5 of them $90-92$, 9 of them $85-89,32$ of them $80-84$, etc.). The oldest man runner to reach the finish line is Jiří Soukup. He was able to finish the race at the age of 91 years and 3 months in the year 2018. The oldest woman runner was Dana Ellingerová at the age of 80 years, 7 months and 12 days in 2018.

The first step for formation of motivation was to arrange age categories and announce the winners (the three best runners received awards). This routine practice 
began in 1956 for runners older than 40 years old. Later it was necessary to arrange more and more categories - now there are 9 categories at 5 -year intervals, the last one is for men runners over 80 . Women runners have a similar system, the last category being for women over 70 .

Yet what about runners who do not have the chance to stand up on the winners' podium? Our experience has shown that in-depth statistics concerning performances from a long-term perspective can help every participant to find an appropriate competition, and thereby gain the motivation to continue. Wider publicity is also helpful here, of course. To publish rankings in the greatest possible span is desirable - almost every runner can find his name here.

To this end the special tables and rankings (in all time ranges) were completed during the last 30 years. Now we can offer these:

- 50 best performances for each age group (both men and women);

- 3 best performances for each age, year by year (starting from 40 and then each year consecutively up to age 87); the same for women (from 35 up to 72);

- how many times runners were able to run under $35,40,45,50,55$, or 60 minutes (10-50 results for each item);

- which men runner had the best average of 2, 3, 4, up through 25 and 30, 35, 40 and 50 starts; the same for women up to 30 starts (1-10 results for each item);

- which runner had the best performance of the 1st, 2nd, 3rd up to 50th runs, comparing the results from personal rankings.

In other words, not only long-standing engagement but also long-standing performances are appreciated. ${ }^{9}$ Runners confirmed that these aspects are important for their motivation to participate at this traditional race. They received the question: "What motivates you to repeatedly participate in 'Běchovice - Praha'?” Six possible answers were offered ${ }^{10}$ and here is the ranking of the results:

The fact that the route is the same each year and so I can compare my performance in long-standing perspective (19.4\%).

1. The "big" tradition of the oldest road race on the European Continent (19.0\%).

2. The chance for an annual encounter with friends and fellow runners (18.4\%).

3. The "small" tradition of individuals, families, or groups, of which I became part (14.9\%).

4. The fact I can follow my progress in rankings of number of participations and/or of performance published from 1990 (14.8\%).

5. It is a good test of the fight with age and even death (13.4\%).

There could be a lot of interpretations from these results; we will mention only two. First, the most popular answer shows that the values of this race's runners are in clear opposition to the "obsessive innovators" school of thought. Second, the fight with age and death are not topics that lifelong runners see as important motivation.

9 Some admirable results: 40:58 at 7; 37 times better than 40 minutes; $42: 33$ as average of 50 participations etc.

10 They could choose 1-2 answers, so that percentage is calculated from the sum of answers, not respondents. 
There is also motivation for other types of runners to be part of this tradition. Furthermore, our long-standing monitoring of runners and continuous publishing of our findings had direct influence on runners' activities.

\section{DISCUSSION}

The theoretical part of our text was concluded with our own definition of tradition. We tried to embrace more facets of it and embed it in the concept of social time. Of course, this may be opened for further discussion and critique.

Further, we tried to determine the role of tradition in the field of sports. We spoke a lot of tradition of the Olympic Games and the differences in progression between the ancient traditions of Coubertin's Olympism and those of the Sokol. Yet another approach is shown in the Maccabiah Games, held in Israel starting in the year 1932. Every four years, the best Jewish athletes from throughout the world compete in them. Two differences are seen here from a cursory consideration. First, the heritage of Coubertin's Olympism is combined with the Jewish history. Second, the Games are arranged not only for elite athletes but also include Open, Masters, Juniors and Disabled competitions as well. The Maccabiah Games present an opportunity for further research.

However, optimism concerning the high role of tradition in the sports world may be tempered if we have a look at key values of sports organizations, important events or different approaches of sports theory. For example, Myles Brand, president of the National Collegiate Athletic Association in 2003-2009, named eight key values of the NCAA but did not mention Tradition (Brand, 2006). Furthermore, Scott Kretchmar named in his chef d'oeuvre four non-moral values and multiple moral values, but tradition was missing (Kretchmar, 2005). We can find tradition as an important value in the football club Bayern Münich. Here tradition is named alongside partnership, respect, responsibility and seven further values.

There is rather strange situation within Olympism: the Olympic Charter speaks enough about history of modern Olympism yet a link with the ancient tradition is missing in the text.

Surprisingly, tradition is the most often mentioned within sports business, where it is seen as an effective marketing tool. Experts from this area have recognized that to be joined with some traditional race or event can improve "brand awareness". This is the case both of great international sports events and of smaller running races in the Czech Republic whose history begins before $1945 .{ }^{11}$ Two traditional Slovak races, the Košice Peace Marathon (from 1924 $4^{12}$ ) and the National Race Devín - Bratislava (from 1921) ought to be mentioned as well. No organizer of these events forgets to mention how old the run is and which anniversary is being celebrated that year.

Tracking running activities through one traditional race has enabled us to understand how tradition can build and strengthen motivation to be active up to an older

13 races of them still continue and were organized in 2018.

12 It is the oldest European marathon, organized annually with exception of the years 1938 a 1940. 
age. ${ }^{13}$ This lifelong perspective can also encourage former elite athletes to continue in their sports activities after retirement. Yet if we look at the numbers of elite versus non-elite repeat participants, the non-elite runners far outnumber the elites. On examining the list of 322 loyal runners, only six medalists of the main race were found.

A secondary question that arises is whether length of running career in running contributes to longevity. According to our special group of runners, this appears to be the case: deceased runners died at a higher average age than the lifespan of the average Czech male population. However, additional research is needed to examine this supposition. Is there some similar longitudinal study, or in-depth statistical processing of some concrete race as a possible base for such a study? Among the running races in the Czech Republic beginning their history before 1945, only one other pays tribute to loyal runners (having run the race 20 times and more) and publish ranking of them. They are rewarded with special starting numbers according this ranking (the runner with highest number of participations receives number 1).

Among international races there is a natural comparison with "the Everest of all marathons": the Boston Marathon. Also founded in 1897 ("Běchovice - Praha" is some weeks younger), there is no break during its history, and there has been a steadily increasing number of runners. Of course, the international fame has no comparison, and to be a finisher of a marathon (especially the Boston Marathon) is more appreciated than in the case of $10 \mathrm{~K}$. Concerning statistics, we can find complete results on the web pages of the Boston Athletic Association, as well as surveys of the number of participants, age groups, or nationalities. Personal statistics of individual runners are not published on these pages, but the legendary John A. Kelley, who won the race in 1935 and again in 1945, is mentioned among the race "milestones". His mention is not due to these two wins but because he started a record 61 Boston Marathons and finished 58. His final race came in 1992 at the age of 84 . He symbolizes the tradition and spirit of the race. His running longevity and loyalty are strong inspiration for a lot of athletes, and not only runners. This is just what we want to promote as well.

Wider publicity was given to another remarkable running act - the record for most consecutive Boston Marathons completed by Bennett Beach (50 runs on April 17, 2017). What may be more interesting (having in view our effort to promote long-standing running activity) is the fact that Beach is a leader of the list of what Boston Marathon organizers call "streakers". These "streakers" were able to run the whole Boston Marathon at least 25 times in a row without break. They have a special club, the Quarter Century Club. It was first formed by Ronald Kmiec in 2001 and after the run in 2017, it boasts 129 members including 9 women (McGillivray, 2017).

Though the achievements of all members of the Boston Marathon Quarter Century Club are beyond question, we would like to dispute one questionable topic: isn't it dangerous to promote non-stop participation, and not "only" the sum of all personal entries, reached perhaps with some breaks? We are addressing hazards to athletes' health. Long-distance runners are strong-willed people - that classification applies twofold to "streakers". Yet this can be positive or negative. Sometimes our mind or will can be stronger than our body. Continuing to run the race at any price can lead to

13 We focused on motivation and lifestyle of long-standing runners in (Bednár \& Malinauskas, 2014). 
collapse. We decided not to publish the full ranking of "Běchovice streakers" after the on-course death of one runner with a known motivation. We have rather decided to prefer the ranking of the sum of all participations for each runner.

In the field of sport science, we can see often analyses of elite runners, or comparisons of different aspects of the World Marathon Majors - e.g. (Maffetone et al., 2017), in which authors analyzed the race times of the top 10 male and 10 female finishers of all races in the WMM for the years 2005-2014. Closer to our aim to find factors leading to long-standing engagement of runners in traditional races is the research of (Burdina et al., 2017). They analysed (using the Boston Marathon data from 1970 to 2015) the effect of goal attainability on performance - and in fact on participation itself - across age groups. They examined the fact that performances are better at the point of entrance into the older age group. They argue that runners have better chance to fulfil the strict qualifying standards within the Boston Marathon, therefore their motivation and effort are stronger. We can confirm this the same phenomenon - that the performances at the top of ranking for age 40, 45, 50, etc. are better than those "around" those ages (at age 41, 44, 46, 49, 51, etc.), yet the motivation is different. The motivation becomes simply to reach a better position in rankings for the older age group ("Běchovice - Praha” has no qualifying standards).

Orientation on the oldest age groups was presented in (Ahmadyar et al., 2016). Authors followed-up performance of elderly marathoners ( $>75$ years) competing in the world's largest marathons between 1990 and 2014. Participation and performance trends were examined, yet relation to tradition was not mentioned.

The author of a study concerning the development of long-distance racing in Japan (Havens, 2015) aims to more closely evaluate connection between tradition and running. The author accomplishes this by using wide historical, cultural, social, and sports background. After 1912, the Japanese government used athletics as part of its project to achieve parity with the world powers and distance racing became a proper instrument in this effort. Later, commercial media companies promoting especially marathons and ekiden (long-distance relays) played an important part in building the new running tradition.

We could see that in all mentioned studies participation and performance general trends are investigated - we try to present personal running "stories in numbers" of one traditional race across its whole lifespan. During our longitudinal study we have also tried to influence runners using multiple statistics as competitions of their own type and instrument to join runners with tradition of the race. To the best of our knowledge, our approach is the first one of this type.

\section{CONCLUSION}

How to strengthen the role of tradition and building loyalty to it? We can summarize findings from the running area using research of one traditional race.

- To keep the same route - it can have the effect of a special genius loci; it enables comparison of performances in the whole active period of life.

- To arrange competitions - for all runners of any age. Arrange it and publish results. One way is to appreciate the number of starts - to publish regularly the list of loyal runners; to pay tribute to those who reached high number of participations. Another 
way - for more ambitious runners with orientation on performance - is to administer special lists of the best results within the lifelong perspective.

- To arrange special celebrations of anniversaries.

- To support branching of tradition - we followed the case of loyal families; it could be extended for clubs, or special teams (colleagues from one organization, schoolmates, etc.).

- The number of attendees can be ambivalent factor. Organizers ought to find the optimal number: too small is dangerous for survival of tradition, too big a crowd (see some city marathons) can lead to loss of certain exclusivity, or of "magic" of the race or event. To offer preference to loyal athletes can be the good rule here.

Let's finish with words of Dave McGillivray, the race director of the Boston Marathon: "It's a personal honor to share this unique comradery (members of the Boston Marathon Quarter Century Club) ... They all are now deeply engrained in the history and tradition of the most prestigious marathon in the world" (McGillivray, 2017, p. 9).

\section{ACKNOWLEDGEMENTS}

This work was supported by the Charles University under Grant Progres Q19.

\section{REFERENCES}

Ahmadyar, B., et al. (2016). Improved race times in marathoners older than 75 years in the last 25 years in the world's largest marathons. The Chinese Journal of Physiology, 59(3), 139-147.

Bednář, M. (2011). Běchovice: tradice, kult i motivace (Běchovice: tradition, cult and motivation). Prague: European Science and Art Publishing.

Bednár, M., \& Malinauskas, R. (2014). Sport as the basic contents of leisure in biodromal perspective: an example of long-distance runners. Baltic Journal of Sports \& Health Sciences, 47(4), 2-8.

Brand, M. (2006). The role and value of intercollegiate athletics in universities. Journal of the Philosophy of Sport, 33(1), 17.

Burdina, M., Hiller, S. R., \& Metz, N. E. (2017). Goal attainability and performance: evidence from Boston Marathon qualifying standards. Journal of Economic Psychology, 58 (February), 77-88.

Coubertin, P. de (2000). Olympism: selected writings, ed. Norbert Müller. Lausanne: International Olympic Committee.

Deci, E. L., \& Ryan, R. M. (1985). Intrinsic motivation and self-determination in human behaviour. New York: Plenum.

Elchardus, M. (1988). The rediscovery of Chronos: the new role of time in sociological theory. International Sociology, 3(1), 35-59.

Gadamer, H.-G. (2004). Truth and method. New York: Crossroad.

Giddens, A. (1994). Living in a Post-traditional Society. In: Beck, U., Giddens, A., \& Lash, S. (Eds.), Reflexive modernization: politics, tradition and aesthetics in the modern social order (pp. 56-109). Cambridge: Polity Press.

Havens, T. R. H. (2015). Marathon Japan: distance racing and civic culture. Honolulu: University of Hawai Press.

Hobsbawm, E., \& Ranger, T. (Eds.) (1992). The invention of tradition. Cambridge: University Press.

Kretchmar, S. R. (2005). Practical philosophy of sport and physical activity. Champaign, IL: Human Kinetics. 
Maffetone, P. B., et al. (2017). The Boston Marathon versus the World Marathon Majors. PLoS One, 12(9), e0184024.

McGillivray, D. (2017). The Quarter Century Club of the Boston Marathon. The Streak Registry, 17(2), 9-14.

Nolte, C. E. (2009). Our brothers across the ocean: The Czech Sokol in America to 1914. International Journal of the History of Sport, 26(13), 1963-1982.

Shils, E. (1981). Tradition. London and Boston: Faber \& Faber. 